\title{
The Newcastle satisfaction with nursing scales in a Mexican Oncology Hospital
}

\author{
Cecilia Rodríguez-Herrera ${ }^{1}$, José de Jesús López-Jiménez ${ }^{2,3}$, Azucena del Toro-Valero ${ }^{1}$, Nora Magdalena \\ Torres-Carrillo ${ }^{4}$, Norma Torres-Carrillo ${ }^{4}$, Carlos Alberto Godínez-Peña ${ }^{5}$, Ana Cecilia Méndez-Magaña ${ }^{6}$, \\ Melva Guadalupe Herrera-Godina ${ }^{7}$, Ana Lilia Fletes-Rayas ${ }^{8}$
}

1. Instituto Jalisciense de Cancerología.

2. Instituto Mexicano del Seguro Social, Centro de Investigación Biomédica de Occidente, División de Medicina Molecular.

3. Universidad de Guadalajara, Centro Universitario de Ciencias de la Salud, Departamento de Disciplinas Filosófico Metodológico e Instrumentales; Departamento de Morfología.

4. Universidad de Guadalajara, Centro Universitario de Ciencias de la Salud, Departamento de Microbiología y Patología.

5. Universidad de Guadalajara, Centro Universitario de Ciencias de la Salud, Departamento de Fisiología.

6. Universidad de Guadalajara, Centro Universitario de Ciencias de la Salud, Departamento de Salud Pública.

7. Universidad de Guadalajara, Centro Universitario de Ciencias de la Salud, Departamento de Psicología Aplicada.

8. Universidad de Guadalajara, Centro Universitario de Ciencias de la Salud, Departamento de Enfermería Clínica Aplicada.

\begin{abstract} could be used on cancer patients.

DOI: https://dx.doi.org/10.4314/ahs.v21i1.10 abs.v21i1.10

\section{Introduction}

Patient satisfaction is defined as the subjective evaluation (cognitive and emotional responses) that results from the interaction between a patient's expectations with respect to nursing care (ideal) and her/his perceptions of the actual nursing care ${ }^{1}$. Patient satisfaction is also defined as a combination of experiences, expecta-
\end{abstract}

Objectives. The principal aim of this study was to identify whether the Newcastle Satisfaction with Nursing Scales (NSNS)

Methods. This was a descriptive, cross-sectional study carried out on cancer patients ( $\mathrm{n}=298$ ).

Results. We found that a majority of cancer patients were around 50 years old (hospitalized patients [HP]: $49.5 \pm 14.9$; chemotherapy outpatients [COP]: $49.4 \pm 12.7$ ), were female (HP: 74\%; COP: 63.5\%), and had received education at least up to elementary level (HP: 70\%; COP: 80\%). Breast cancer was the principal type of cancer (>34\%) in both groups (HP and COP). The groups were comparable in age, sex distribution, place of origin, educational qualification, and type of cancer. Among HP, the experience and satisfaction scales of the NSNS showed good internal consistency ( $\mathrm{n}=235, \alpha>0.9, \mathrm{r}>0.7$ ), while among COP, only the satisfaction scale showed good internal consistency $(\mathrm{n}=62, \alpha=1.00)$. Most patients' perceptions (level of satisfaction) of hospitalization and chemotherapy services were positive ( $98 \%$ and $97 \%$, respectively).

Conclusion: An NSNS instrument specifically designed for ambulatory care cancer patients is necessary for it to be useful in assessing cancer patients' perception of nursing care. This will help improve the quality of care in Mexico.

The presence of cancer by itself could modify the patients' satisfaction level. Further large-scale studies are required to investigate the patients' perceptions of nursing care using the NSNS on different cancer patient groups.

Keywords: Spanish satisfaction tool; hospital; patient satisfaction; oncology nursing; health care evaluation mechanisms.

Cite as: Rodriguez-Herrera C, López-Jiménez J- d-J, del Toro-Valero A, Torres-Carrillo NM, Torres-Carrillo N, Godinez-Peña CA, et al. The Newcastle satisfaction with nursing scales in a Mexican Oncology Hospital. Afri Health Sci. 2021;21(1):60-6. https:/ / dx.doi.org/10.4314/

\section{Corresponding author: \\ Ana Lilia Fletes Rayas, \\ Universidad de Guadalajara, Centro Universitario de \\ Ciencias de la Salud, Departamento de Enfermería \\ Clínica Aplicada. Phone: +52-33-1058-5200 ext. 34098, \\ E-mail: anna.fletes@gmail.com, \\ lilia.fletes@academicos.udg.mx}

tions, and needs to be perceived ${ }^{2}$. Patients' opinions and subjective perceptions of the care they have received are regarded as important for quality improvement as they provide knowledge about the quality of health services $^{3,4}$.

The quality of health services in Mexico is evaluated by a set of health quality indicators called "Sistema Nacional de Indicadores de Calidad en Salud" (INDICAS). The INDICAS is used to monitor and compare the quality of medical units across the country through nursing supervisors to accurately assess the technical procedures of the nurses under their charge. However, this system neglects the patients' subjective perceptions of the received care. INDICAS quality assessment sys-

(1) Rodriguez-Herrera $\mathrm{C}$ et al, Licensee African Health Sciences. This is an Open Access article distributed unde tribution License (https://creativecommons.org/licenses/BY/4.0), which permits unrestricted use, distribution, and reproduction in any medium, provided the original work is properly cited.

African Health Sciences, Vol 21 Issue 1, March, 2021 
tem belongs to "Sistema Integral de Calidad en Salud" (SICALIDAD). SICALIDAD considers the patients' opinions of their treatment and attention given by medical personnel ${ }^{5}$. Unfortunately, this system contains generalized questions focusing on the relationship with "medical and nursing personnel," and it does not comprehensively assess patients' perceptions of nurses and nursing care.

The Newcastle Satisfaction with Nursing Scales (NSNS) is regarded as an accurate assessment of patients' perceptions of nursing care. It is used to assess the views of users of health services in order to guide the development and progression of quality care in nursing units ${ }^{6}$.

Brazil was the first Latin American country to assess patients' perception of care using the NSNS7. Several other countries have used the NSNS as well, including Ethiopia, Turkey, Poland, Italy, Malaysia, the UK, and Canada ${ }^{6,8-15}$. In the Americas, there is still little information on care perception and satisfaction among patients using the NSNS questionnaire ${ }^{10,16}$. Furthermore, the NSNS has been used to assess patient satisfaction across diverse areas of nursing care and specialties (e.g., intensive care, medical and surgical nursing), and for different patient types (e.g., adolescents and adults). However, the NSNS has been applied neither to cancer patients nor to patients in Mexico. In Guadalajara city (Jalisco state), public hospitals provide health services to a large numbers of patients with cancer. In a public oncology hospital, the data shows that 127,462 medical consultations were granted between 2013 and 2018.

The aim of this study was to identify whether the NSNS could be used on Mexican cancer patients belonging to a public oncology hospital.

\section{Methods}

This was a descriptive cross-sectional study; carried out using the NSNS version modified by Dorigan et $\mathrm{al}^{7}$ This questionnaire has previously been translated and validated in a Brazilian population (patients from a public teaching hospital).

We used a sample of 298 patients receiving chemotherapy and care services at a single oncology public uni- versity hospital in Jalisco state, Mexico. Medical records were acquired for all patients. According to the mode of chemotherapy drug delivery, the population surveyed was divided into two groups: hospitalized patients (HP [n = 235]), whose stay lasted more than two days at the hospital, and chemotherapy outpatients (COP [ $\mathrm{n}=$ 63]), whose stay lasted between 1-3 hours. The NSNS was translated from English to Spanish and tropicalized by two independent experts. During NSNS application, nurses were present to address patients' doubts in order to maintain instrument validity and reliability (Experiences of Nursing Care Scale [Cronbach's $\alpha=0.86$, Satisfaction with Nursing Care Scale [Cronbach's $\alpha=$ $0.97]^{16}$.

\section{Ethical considerations}

Written informed consent was obtained from all patients prior to the study. All procedures were approved by the institutional review board (number 014/16).

\section{Data analysis}

The NSNS is rated on a seven-point Likert scale (modified by Dorigan et al. ${ }^{7}$ ) (Table 1) and consists of two separate scales: the Experiences of Nursing Care Scale ("A") and the Satisfaction with Nursing Care Scale ("B"). The "A" scale evaluated the experience of the nursing care as perceived by the patients and contained 26 items (eleven items were negatively worded and therefore were reverse scored). The "B" scale evaluated patient satisfaction with how the nursing staff carried out nursing interventions and care. The NSNS was applied without changes for the HP group. However, as the outpatient chemotherapy service is provided only during the morning and afternoon shifts, all items referring to the night shift were removed for the COP group. This resulted in five items being eliminated-four from the " $\mathrm{A}$ " scale ("The nursing team turned the lights off too late at night," "The nursing team explained what they were going to do to me before they did it," "The nursing team used to go away and forget what patients had asked for," and "The nursing team did not seem to know what each other were doing") and one from the "B" scale ("The amount the nursing team knew about your care"). 
Table 1. Internal consistency of the Newcastle Satisfaction with Nursing Scales for two hospital service areas and score values by service.

\begin{tabular}{|c|c|c|c|c|c|c|c|}
\hline \multirow[b]{3}{*}{$\begin{array}{l}\text { Hospitalization } \\
\text { group }(n=234)\end{array}$} & \multicolumn{2}{|c|}{ Experience Scale items } & \multicolumn{2}{|c|}{ Satisfaction Scale } & \multicolumn{3}{|c|}{$\alpha(r)$ Values } \\
\hline & \multicolumn{4}{|c|}{ Cumulative score expressed by X, SD (Min-Max) } & A It & & B Items \\
\hline & \multicolumn{2}{|c|}{$58 \pm 1.2(46-60)$} & \multicolumn{2}{|c|}{$99.1 \pm 0.3(85.7-100)$} & \multicolumn{2}{|c|}{$0.94(0.75)$} & $0.94(0.91)$ \\
\hline \multirow{2}{*}{$\begin{array}{l}\text { Outpatient } \\
\text { chemotherapy group } \\
(n=62)\end{array}$} & \multicolumn{2}{|c|}{$64 \pm 0.4(62.9-65.2)$} & \multicolumn{2}{|c|}{$99.3 \pm 0.2(98-100)$} & \multicolumn{2}{|c|}{$0.58(0.66)$} & 1.000 \\
\hline & \multicolumn{2}{|c|}{ Hospitalization group } & \multicolumn{2}{|c|}{$\begin{array}{l}\text { Outpatient } \\
\text { chemotherapy group }\end{array}$} & \multicolumn{2}{|c|}{$\begin{array}{l}\text { Cut off } \\
\text { points }\end{array}$} & \\
\hline $\begin{array}{l}\text { Level of satisfaction, } \\
\text { TOTAL A+B. } \\
\text { X, SD (Min-Max), n }\end{array}$ & \multicolumn{2}{|c|}{$\begin{array}{l}75 \pm 1.2(66-77) \\
n=234\end{array}$} & \multicolumn{2}{|c|}{$\begin{array}{l}79.4 \pm 0.1(79.2-80) \\
n=62\end{array}$} & & & \\
\hline \multirow{2}{*}{$\begin{array}{l}\text { Level of Satisfaction, } \\
\text { n (\%). Via } \\
\text { demarcation } \\
\text { threshold formula }\end{array}$} & \multicolumn{2}{|c|}{ Fully satisfied = $230(98 \%)$} & \multicolumn{2}{|c|}{$\begin{array}{l}\text { Fully satisfied }=60 \\
(97 \%)\end{array}$} & \multicolumn{2}{|c|}{$72^{\dagger}$} & \\
\hline & \multicolumn{2}{|c|}{ Not Fully satisfied $=4(2 \%)$} & \multicolumn{2}{|c|}{$\begin{array}{l}\text { Not Fully satisfied }=2 \\
(3 \%)\end{array}$} & \multicolumn{2}{|c|}{$80^{*}$} & \\
\hline \multicolumn{8}{|c|}{ Ordinal Scale NSNS instrument } \\
\hline \multirow{3}{*}{$\begin{array}{l}\text { Decoding, qualitative } \\
\text { ordinal scale }^{\S}\end{array}$} & $\begin{array}{l}\text { Disagree } \\
\text { Completely }\end{array}$ & $\begin{array}{l}\text { Disagree } \\
\text { a lot }\end{array}$ & $\begin{array}{l}\text { Disagree } \\
\text { a Little }\end{array}$ & $\begin{array}{l}\text { Neither } \\
\text { Agree } \\
\text { nor }\end{array}$ & $\begin{array}{l}\text { Agree } \\
\text { a little }\end{array}$ & $\begin{array}{l}\text { Agree } \\
\text { a lot }\end{array}$ & $\begin{array}{l}\text { Agree } \\
\text { completely }\end{array}$ \\
\hline & 1 & 2 & 3 & 4 & 5 & 6 & 7 \\
\hline & $\dagger 6$ & $\dagger 5$ & $\dagger 4$ & $\dagger 3$ & $\dagger 2$ & ${ }^{\dagger} 1$ & ${ }^{\dagger} 0$ \\
\hline
\end{tabular}

\footnotetext{
$\mathbf{X}=$ Average, $\mathbf{M i n}=$ Minimum, $\mathbf{M a x}=$ Maximum, $\mathbf{S D}=$ Standard Deviation

$\boldsymbol{\alpha}=$ Cronbach's alpha, $\S=$ upper (Items) and down [positive and ${ }^{\dagger \dagger}$ negative questions

(inversely proportional score)].

$\dagger=$ Cut off point calculated using the demarcation threshold formula in Hospitalization service. $\$=$ Cut of point calculated using the demarcation threshold formula in Outpatient chemotherapy service.
}

The analysis was performed using SPSS (Statistical Package for the Social Sciences) v. 25 for Windows (IBM, Armonk, NY, USA). The internal consistency of the NSNS was confirmed via the Cronbach's $\alpha$ coefficient and Pearson's correlation coefficient $r$ (good reliability was considered when the Cronbach's $\alpha$ was $\geq 0.70$ and the $\mathrm{r}$ was $\geq 0.60)^{17}$.

Patient satisfaction was assessed by classifying participants into two groups: fully and not fully satisfied, using a cutoff point calculated via the demarcation threshold formula: [(total highest score - total lowest score)/2] + total lowest score ${ }^{8}$. As shown in Table 1, the cutoff point calculated by this formula for the HP group was 72; therefore, participants with scores of less than 72 were considered not fully satisfied and those with scores greater than 72 were considered as fully satisfied. For the COP group, the cutoff point was 79.6.

\section{Results}

Patient characteristics are listed in Table 2. The groups were comparable in mean age, sex distribution, birthplace, educational qualification, and type of cancer $(\mathrm{p}=$ $0.05-1)$ but differing in marital status $(p=0.00)$. The mean age of patients was close to 50 years; most of them were females and had received education at least up to elementary level. Complete data are presented in Table 2. 
Table 2. Demographic characteristics of cancer patients.

\begin{tabular}{|c|c|c|c|c|}
\hline & & $\begin{array}{l}\text { Hospitalization } \\
\text { service }(n=235)\end{array}$ & $\begin{array}{l}\text { Outpatient } \\
\text { chemotherapy } \\
\text { service } \\
(\mathrm{n}=63) \\
\end{array}$ & $p$ \\
\hline \multicolumn{2}{|c|}{ Age (years), $\overline{\mathrm{x}} \pm \mathrm{SD}$ (range) } & $\begin{array}{l}49.5 \pm 14.9(19- \\
83)\end{array}$ & $49.4 \pm 12.7(27-77)$ & $0.97^{*}$ \\
\hline $\begin{array}{l}\text { Sex distribution, } \mathrm{n} \\
(\%)\end{array}$ & $\begin{array}{l}\text { Female } \\
\text { Male }\end{array}$ & $\begin{array}{l}174(74) \\
61(26)\end{array}$ & $\begin{array}{l}40(63.5) \\
23(36.5)\end{array}$ & $0.12^{* * *}$ \\
\hline Marital status, n (\%) & $\begin{array}{l}\text { Married } \\
\text { Single } \\
\text { Widowed } \\
\text { Divorced }\end{array}$ & $\begin{array}{l}157(66.8) \\
52(22.1) \\
26(11.1) \\
0\end{array}$ & $\begin{array}{l}48(76.2) \\
6(9.8) \\
2(3.2) \\
7(11.1)\end{array}$ & $\mathbf{0 . 0 0}^{* *}$ \\
\hline $\begin{array}{l}\text { State of Mexico, } n \\
(\%)\end{array}$ & $\begin{array}{l}\text { Jalisco } \\
\text { Others }\end{array}$ & $\begin{array}{l}197(84) \\
38(16)\end{array}$ & $\begin{array}{l}53(84) \\
10(16)\end{array}$ & $1.00^{* *}$ \\
\hline Education, n (\%) & $\begin{array}{l}\text { Illiterate } \\
\text { Primary school } \\
\text { High school }^{\dagger} \\
\text { University }\end{array}$ & $\begin{array}{l}35(15) \\
166(70) \\
25(11) \\
9(4)\end{array}$ & $\begin{array}{l}6(10) \\
51(80) \\
6(10) \\
0\end{array}$ & $0.29^{* *}$ \\
\hline $\begin{array}{l}\text { Cancers by Body } \\
\text { Location/System, } \\
\text { n }(\%)\end{array}$ & $\begin{array}{l}\text { Breast } \\
\text { Gynecologic } \\
\text { Digestive/ } \\
\text { Gastrointestinal } \\
\text { Hematologic/Blood } \\
\text { Musculoskeletal } \\
\text { Genitourinary } \\
\text { Head and Neck } \\
\text { Skin } \\
\text { Neurologic } \\
\text { Other }\end{array}$ & $\begin{array}{l}97(41.3) \\
47(20) \\
39(16.6) \\
13(5.5) \\
11(4.7) \\
10(4.3) \\
8(3.4) \\
4(1.7) \\
3(1.3) \\
3(1.3)\end{array}$ & $\begin{array}{l}22(34.9) \\
8(12.7) \\
13(20.6) \\
11(17.5) \\
0 \\
6(9.5) \\
2(3.2) \\
1(1.6) \\
0 \\
0\end{array}$ & $0.05^{* *}$ \\
\hline
\end{tabular}

Using the demarcation threshold formula, the total score (experience scale "A" + satisfaction scale "B") for the HP group was near to the maximum value (corresponding to fully satisfied, as shown in Table 1). The same was true for the COP group. Factor analysis techniques, including the Bartlett and Kaiser-Meyer-Olkin test, were not performed due to maximum score being achieved for the majority of positive items. This behaved like a forced-choice test and produced results that were like ipsative data.

Table 1 shows the Cronbach's $\alpha$ and correlation coefficients used to validate the NSNS applied to patients, contrasting between paired and non-paired items. Items in " $\mathrm{A}$ " and " $\mathrm{B}$ " were analyzed for both services. Only the " $\mathrm{A}$ " scale in the COP group did not show good internal consistency $(\alpha=0.58$ and $r=0.66$ ) (Table 1$)$.

Table 1 shows the mean item scores of the two scales broken down by patient service. Interestingly, the mean scores for the "A" scale were rather low for both patient groups owing to the negatively worded items, which had relatively high scores before being reversed. Using the demarcation threshold formula, the mean scores of the " $\mathrm{B}$ " scale indicated that patients' perceptions were resoundingly positive (near to the maximum score) for both groups. The total NSNS scores for both patient groups are also shown in Table 1. According to the above cutoffs, more than $96 \%$ of participants were fully satisfied with the hospitalization and outpatient chemotherapy services (Table 1).

\section{Discussion}

The INDICAS and SICALIDAD are government programs focused on evaluating the quality of health services across Mexico. Both systems have limitations that delay the fulfillment of governmental objectives. The INDICAS system has a limited coverage (participating units do not exceed half of the total in Mexico); in addition, the participation of private institutions is nil ${ }^{18}$. 
The patients' perception of nursing care is evaluated only in terms of the care received through the dichotomous response to 11 questions that do not comprehensively evaluate the patients' perception of nursing staff and nursing care. On the other hand, NSNS is focused particularly on patients' perceptions about the nursing service.

Concerning the SICALIDAD system, quality managers who are responsible for filling and analyzing data devote their time to various functions, not all of which are necessarily related to the operation of SICALIDAD. A relevant aspect is that the evaluation and reporting of results in INDICAS and SICALIDAD are carried out by personnel belonging to the evaluated institution, which prevents timely monitoring of quality and reliability ${ }^{19}$.

Notably, the NSNS scale has been used widely across Europe $^{6,9,11,13}$, but in the Americas, it only has been applied in Canada and Brazil7,10, and it has not, until now, been used to assess cancer patients.

In assessing the reliability of the NSNS in both patient services, we found that the Cronbach's a and correlation coefficient of the " $\mathrm{A}$ " scale were insufficient for the COP group $(\alpha=0.58, \mathrm{r}=0.6612)$ (Table 1). This might be because the COP group has a short stay in the service and the NSNS was not specifically designed for ambulatory care.

In the hospitalization area, by contrast, the Cronbach's a was high (Table 1). Greater homogeneity and internal consistency were observed in the responses. This indicates that the NSNS is well suited and easily understood by these patients, similar to Dorigan et al.'s findings ${ }^{16}$.

With respect to the level of satisfaction with nursing care, $96 \%$ of cancer patients were fully satisfied (see Table 1). Furthermore, in both services, the mean score on the experience and satisfaction scales was close to 60 and 90, respectively (Table 1). In other countries, fewer percentage of patients were satisfied with nursing care $^{8,12,13}$.

Regarding the causes of annoyance in patients in this study, the following experiences were rated most negatively: "The nursing team favored some patients over others," "The nursing team made me do things before I was ready," "The nursing team let things get on top of them," "The nursing team used to go away and forget what patients had asked for," and "The nurses did not seem to know what the other members of the nursing staff were doing." Most of the items (>95\%) in the hospitalization and chemotherapy services were scored with the highest values (rated most negatively) without finding a modal factor. In one descriptive study, it was found that the sleep disturbances factor was the major cause of annoyance ${ }^{13}$. Our results were not in accordance with Uğraş et al.'s findings ${ }^{13}$, in that we did not find a principal annoyance factor. With respect to the high negative score for one NSNS scale item, several studies $^{8,16,20,21}$ reported similar results to Uğras et al. ${ }^{13}$. Interestingly, Gutysz-Wojnicka et al.9 reported that in university hospitals, the total satisfaction score was lower in comparison with provincial and district hospitals? The hospital analyzed in this study was a university hospital, and the overall rate of full satisfaction was close to $95 \%$.

It is currently recognized that satisfaction can be affected by various factors-i.e., older people, females, and less educated patients tend to assign high scores ${ }^{20-22}$. In the present study, most of the patients presented a high level of satisfaction; however, cancer patients had some capable factors to influencing their high scores, including sex, age, and level of education. It is also likely that the presence of cancer by itself could influence the assignment of high scores.

As noted above, the scores for the COP group were overly high (relative to the cutoff point calculated using the demarcation threshold formula), perhaps due to their short stay. On the other hand, the "A" scale scores were comparatively low, which could be because the NSNS was not designed for use in a public hospital wherein nurses' attention is influenced by a diverse range of factors, such as the short time allocated to care for each patient.

To the best of our knowledge, this is the first study to evaluate patient satisfaction in Mexico and to be applied to cancer patients using the NSNS. The analyzed hospital primarily treats a vulnerable population, as it is a specialized public hospital. Therefore, the questionnaire should be modified according to the hospital, the service, and the characteristics of the patients-i.e., the results of the present study may not represent reality for other hospitals, which is a potential limitation of the present study.

\section{Conclusion}

The NSNS instrument is a useful tool for improving the quality of Mexican oncological health services and must be modified according to the hospital and service needs. The questionnaire showed good internal consistency and objectivity, especially in cancer patients who 
are hospitalized for longer intervals, and could be applied to other hospitals in Mexico. An NSNS instrument specifically designed for ambulatory care cancer patients is necessary. The presence of cancer could modify the level of patient satisfaction. Further largescale studies are required to investigate patients' perceptions of nursing care using the NSNS across the Americas, and on different patient groups.

\section{Acknowledgements}

The authors wish to thank the nursing staff, comprising Emma Alejandra García Olivares, Felicitas Aguirre Rosas, Gloria Guzmán Hernández, Soledad Fregoso Orizaga, Lorena Orozco a la Torre, Elba Susana Gutiérrez Martínez, and Miriam Encina Ruíz, for its valuable support in administration of the NSNS instrument on patients. The authors thank NP Tania Diaz Delgado and Daniela Carolina Raygoza for their valuable revisions of the manuscript, and especially thank the cancer patients for their participation in this study. The authors would like to thank the NSNS team from Newcastle University for their recommendations and permissions to use the NSNS questionnaire in this study.

\section{Conflict of interest}

None declared.

\section{References}

1. Johansson P, Oléni M, Fridlund B. Patient satisfaction with nursing care in the context of health care: a literature study. Scand J Caring Sci. 2002;16(4):337-344.

2. Merkouris A, Ifantopoulos J, Lanara V, Lemonidou C. Patient satisfaction: a key concept for evaluating and improving nursing services. J Nurs Manag. 1999;7(1):1928.

3. Merkouris A, Papathanassoglou EDE, Lemonidou C. Evaluation of patient satisfaction with nursing care: quantitative or qualitative approach? Int J Nurs Stud. 2004;41(4):355-367. doi:10.1016/j.ijnurstu.2003.10.006 4. Schmidt LA. Patients' perceptions of nursing care in the hospital setting. J Adv Nurs. 2003;44(4):393-399. doi:10.1046/j.0309-2402.2003.02818.x

5. Rivera-Buendía F, Bello-Chavolla OY, Zubieta-Zavala A, Hernández-Ramírez L, Zepeda-Tena C, Durán-Arenas L. [Evaluation of Mexican "Sicalidad" health quality program]. Salud Publica Mex. 2015;57(4):329-334.

6. Thomas LH, McColl E, Priest J, Bond S, Boys RJ. Newcastle satisfaction with nursing scales: an instrument for quality assessments of nursing care. Qual Health Care. 1996;5(2):67-72.
7. Dorigan $\mathrm{GH}$, Guirardello E de B, Dorigan $\mathrm{GH}$, Guirardello E de B. Translation and cross-cultural adaptation of the newcastle satisfaction with nursing scales into the brazilian culture. Rev Esc Enferm USP. 2013;47(3):562-568. doi:10.1590/S0080623420130000300006

8. Ahmed T, Assefa N, Demisie A, Kenay A. Levels of Adult Patients' Satisfaction with Nursing Care in Selected Public Hospitals in Ethiopia. Int J Health Sci. 2014;8(4):371-379.

9. Gutysz-Wojnicka A, Dyk D, Cudak E, Ozga D. Measuring patient satisfaction with the Polish version of the Newcastle Satisfaction with Nursing Scale. Scand J Caring Sci. 2013;27(2):311-318. doi:10.1111/j.14716712.2012.01034.x

10. Peterson WE, DiCenso A. A comparison of adolescent and adult mothers' satisfaction with their postpartum nursing care. Can J Nurs Res Rev Can Rech En Sci Infirm. 2002;34(4):117-127.

11. Piredda M, Vellone E, Piras G, et al. Psychometric evaluation of the Newcastle Satisfaction with Nursing Scales. J Nurs Care Qual. 2015;30(1):84-92. doi:10.1097/ NCQ.0000000000000078

12. Tang WM, Soong C-Y, Lim WC. Patient Satisfaction with Nursing Care: A Descriptive Study Using Interaction Model of Client Health Behavior. Int J Nurs Sci. 2013;3(2):51-56.

13. Uğraş GA, Babayigit $S$, Tosun $K$, Aksoy G, Turan $Y$. The effect of nocturnal patient care interventions on patient sleep and satisfaction with nursing care in neurosurgery intensive care unit. J Neurosci Nurs J Am Assoc Neurosci Nurses. 2015;47(2):104-112. doi:10.1097/ JNN.0000000000000122

14. Peterson WE, Charles C, DiCenso A, Sword W. The Newcastle Satisfaction with Nursing Scales: a valid measure of maternal satisfaction with inpatient postpartum nursing care. J Adv Nurs. 2005;52(6):672-681. doi:10.1111/j.1365-2648.2005.03634.x

15. Gungor I, Beji NK. Development and psychometric testing of the scales for measuring maternal satisfaction in normal and caesarean birth. Midwifery. 2012;28(3):348-357. doi:10.1016/j.midw.2011.03.009

16. Dorigan GH, Guirardello E de B, da Silva D, McColl E. Validation of the Brazilian version of the Newcastle Satisfaction with Nursing Scales: a partial least squares path modeling approach. J Nurs Meas. 2014;22(3):451460.

17. Cortina JM. What is coefficient alpha? An examination of theory and applications. J Appl Psychol. 1993;78(1):98-104. doi:10.1037/0021-9010.78.1.98 
18. Cantón SBF. Sistema de indicadores sobre la calidad en salud Proyectos actuales de medición en salud. Boletin Conamed. 2018;4(21).

19. Granados-Cosme JA, Tetelboin-Henrion C, Torres-Cruz C, Pineda-Pérez D, Villa-Contreras BM. [The operation of the health program SICALIDAD: the role of managers in primary care and hospitals]. Salud Publica Mex. 2011;53 Suppl 4:402-406.

20. Akin S, Erdogan S. The Turkish version of the Newcastle Satisfaction with Nursing Care Scale used on medical and surgical patients. J Clin Nurs. 2007;16(4):646653. doi:10.1111/j.1365-2702.2006.01583.x

21. Findik UY, Unsar S, Sut N. Patient satisfaction with nursing care and its relationship with patient characteristics. Nurs Health Sci. 2010;12(2):162-169. doi:10.1111/ j.1442-2018.2009.00511.x

22. Sharew NT, Bizuneh HT, Assefa HK, Habtewold TD. Investigating admitted patients' satisfaction with nursing care at Debre Berhan Referral Hospital in Ethiopia: a cross-sectional study. BMJ Open. 2018;8(5):e021107. doi:10.1136/bmjopen-2017-021107 